\title{
Review
}

\section{Mesenchymal stem cells: a new trend for cell therapy}

\author{
Xin WEI ${ }^{1}$, Xue YANG ${ }^{2}$, Zhi-peng HAN ${ }^{3}$, Fang-fang $\mathrm{QU}^{3}$, Li SHAO ${ }^{1, *}$, Yu-fang SHI ${ }^{2, *}$ \\ ${ }^{1}$ Renji Hospital, Shanghai Jiao Tong University School of Medicine, Shanghai 200127, China; ${ }^{2}$ Key Laboratory of Stem Cell Biology, \\ Institute of Health Sciences, Shanghai Jiao Tong University School of Medicine, Shanghai 200025, China; ${ }^{3}$ Tumor Immunology and \\ Gene Therapy Center, Eastern Hepatobiliary Surgery Hospital, the Second Military Medical University, Shanghai 200433, China
}

\begin{abstract}
Mesenchymal stem cells (MSCs), the major stem cells for cell therapy, have been used in the clinic for approximately 10 years. From animal models to clinical trials, MSCs have afforded promise in the treatment of numerous diseases, mainly tissue injury and immune disorders. In this review, we summarize the recent opinions on methods, timing and cell sources for MSC administration in clinical applications, and provide an overview of mechanisms that are significant in MSC-mediated therapies. Although MSCs for cell therapy have been shown to be safe and effective, there are still challenges that need to be tackled before their wide application in the clinic.
\end{abstract}

Keywords: mesenchymal stem cell; cell therapy; tissue injury; degenerative disease; immune disorder; graft-versus-host disease; immunomodulation; trophic factor

Acta Pharmacologica Sinica (2013) 34: 747-754; doi: 10.1038/aps.2013.50

\section{Introduction}

Stem cells are unspecialized cells with the ability to renew themselves for long periods without significant changes in their general properties. They can differentiate into various specialized cell types under certain physiological or experimental conditions. Cell therapy is a sub-type of regenerative medicine. Cell therapy based on stem cells describes the process of introducing stem cells into tissue to treat a disease with or without the addition of gene therapy. Hematopoietic stem cells (HSCs) have been widely used for allogeneic cell therapy. The successful isolation of pluripotent embryonic stem (ES) cells from the inner cell mass of early embryos has provided a powerful tool for biological research. ES cells can give rise to almost all cell lineages and are the most promising cells for regenerative medicine. The ethical issues related to their isolation have promoted the development of induced pluripotent stem (iPS) cells, which share many properties with ES cells without ethical concerns. However, one key property of ES cells and iPS cells that may seriously compromise their utility is their potential for teratoma formation.

Due to the limitation of using ES and iPS cells in the clinic, great interest has developed in mesenchymal stem cells (MSCs), which are free of both ethical concerns and teratoma

\footnotetext{
* To whom correspondence should be addressed.

E-mail drshaoli@sina.com (Li SHAO);

shiyufang2@gmail.com (Yu-fang SHI)

Received 2013-03-11 Accepted 2013-04-05
}

formation. These cells were first isolated and characterized by Friedenstein and his colleagues in 1974. MSCs, also called mesenchymal stromal cells, are a subset of non-hematopoietic adult stem cells that originate from the mesoderm. They possess self-renewal ability and multilineage differentiation into not only mesoderm lineages, such as chondrocytes, osteocytes and adipocytes, but also ectodermic cells and endodermic cells $^{[1-5]}$. MSCs exist in almost all tissues. They can be easily isolated from the bone marrow, adipose tissue, the umbilical cord, fetal liver, muscle, and lung and can be successfully expanded in vitro ${ }^{[6-10]}$. The number of clinical trials on MSCs has been rising since 2004 (Figure 1). Although the "gold rush" to use MSCs in clinical settings began with high enthusiasm in many countries, with China, Europe and US leading the way (http://clinicaltrial.cn), numerous scientific issues remain to be resolved before the establishment of clinical standards and governmental regulations.

\section{What can MSCs do?}

Currently, there are 344 registered clinical trials in different clinical trial phases (Figure 2) aimed at evaluating the potential of MSC-based cell therapy worldwide. With the advancement of preclinical studies, MSCs have been shown to be effective in the treatment of many diseases, including both immune diseases and non-immune diseases (Figure 3).

MSCs in tissue repair

The wide tissue distribution and multipotent differentiation of 


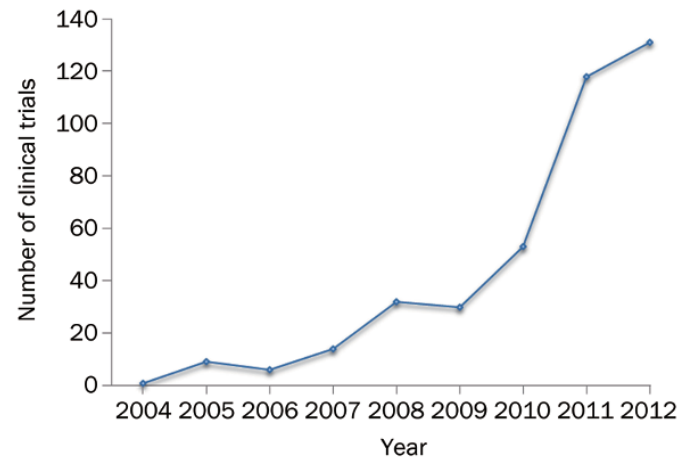

Figure 1. Number of registered clinical trials of mesenchymal stem cellsbased therapy on ClinicalTrials.gov.

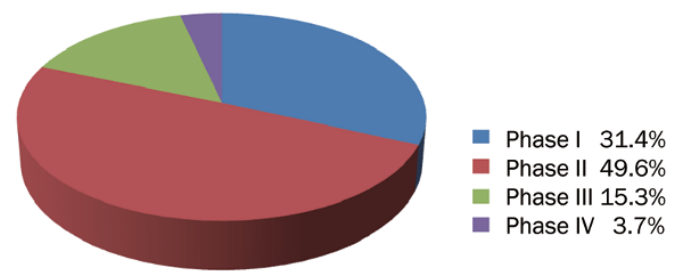

Figure 2. Clinical phages of mesenchymal stem cells-based therapy. Data from ClinicalTrials.gov.

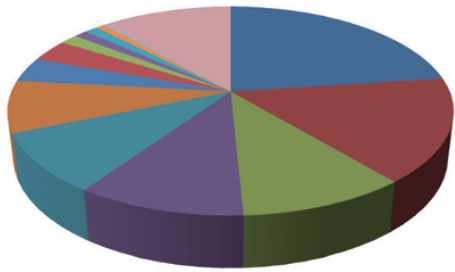

\begin{tabular}{|c|c|}
\hline Myocardial infarction (22.9\%) & Graft versu host disease (16.0\%) \\
\hline Diabetes $(10.3 \%$ & Liver cirrhosis (10.3\%) \\
\hline inal cord injury (9.2\%) & Osteoarthritis (8.0\%) \\
\hline Crobn's disease (3.8\%) & nultiple scllerosis (3.4\%) \\
\hline Aplastic anemia (1.5\%) & Systemic lupus (1.1\%) \\
\hline Rheumatoid arthritis (1.1\%) & Parkinson's disease $(0.8 \%)$ \\
\hline Brain injury $(0.4 \%)$ & Others $(11.0 \%)$ \\
\hline
\end{tabular}

Figure 3. Percentages of the common diseases now treated with mesenchymal stem cells. Data from ClinicalTrials.gov.

MSCs together with the observed reparative effects of infused MSCs in many clinical and preclinical models ${ }^{[11-26]}$ strongly suggest a critical role of MSCs in injury healing. They are believed to be responsible for growth, wound healing, and replacing cells that are lost through daily wear and tear and pathological conditions. Because of these functions, they have been shown to be effective in the treatment of tissue injury and degenerative diseases. In the digestive system, autologous bone marrow mesenchymal stem cells (BM-MSCs) improved the clinical indices of liver function in liver cirrhosis patients and liver failure patients caused by hepatitis $\mathrm{B}^{[27,28]}$. BM-MSCs can also exert strong therapeutic effects in the musculoskeletal system. They have been shown to be effective in the regeneration of periodontal tissue defects, diabetic critical limb ischemia, bone damage caused by osteonecrosis and burn-induced skin defects ${ }^{[29-31]}$. In preclinical studies, investigations by the Prockop team have also shown that human MSCs are effective in treating myocardial infarction ${ }^{[32]}$ and cornea damage ${ }^{[33]}$ through the secretion of tumor necrosis factor-inducible gene 6 protein (TSG-6), which reduces inflammation and promotes tissue reconstruction. A similar phenomenon has been reported for MSCs in treating other tissue injuries, such as the brain, spinal $\operatorname{cord}^{[34]}$ and lung ${ }^{[35,36]}$, all target organs of MSCs in the future. Additionally, co-transplantation of MSCs can enhance the effect of HSCs in treating radiation victims ${ }^{[37]}$.

\section{MSCs in immune disorder therapy}

In addition to their property of treating tissue injury, MSCs are also applied to alleviate immune disorders because MSCs have a powerful capacity of regulating immune responses. Various studies have evaluated the therapeutic effect of MSCs in preclinical animal models and demonstrated great clinical potential. For example, MSCs have been successfully applied to reverse graft-versus-host disease (GvHD) in patients receiving bone marrow transplantation ${ }^{[38,39]}$, especially in patients diagnosed with severe steroid resistance ${ }^{[40-42]}$. Similarly, in systemic lupus erythematosus (SLE) and Crohn's disease patients, both autologous and allogeneic MSCs were able to suppress inflammation and reduce damage to the kidneys and bowel through the possible induction of regulatory $\mathrm{T}$ cells in patients ${ }^{[43-46]}$. It also has been reported that BM-MSCs can improve multiple system atrophy (MSA) ${ }^{[47]}$, multiple sclerosis (MS), amyotrophic lateral sclerosis (ALS) ${ }^{[48-50]}$, and stroke, likely through immediate immunomodulatory effects ${ }^{[51]}$. Osiris' Prochymal, the world's first stem cell drug approved in Canada on May 12, 2012, was successful in phase III clinical trials in treating GvHD and Crohn's disease and has become the only stem cell-based drug approved by FDA ${ }^{[40,52]}$.

\section{Methods and techniques of applying MSCs in the clinic Engraftment of MSCs}

In all of the preclinical and clinical studies, the engraftment of MSCs into damaged tissues via migration to enhance tissue repair/regeneration is a crucial process for clinical efficacy, regardless of the type of organ or specific disease. As more and more clinical studies are performed, the engraftment properties of MSCs are gradually being evaluated in many models and clinical trials. In 2000, a study of human MSC in utero transplantation in sheep demonstrated long-term engraftment as long as 13 months after transplantation, even when cells were transplanted after the expected development of immunocompetence, and the transplanted human MSCs could undergo site-specific differentiation into chondrocytes, adipocytes, myocytes and cardiomyocytes, bone marrow stromal cells and thymic stroma ${ }^{[33]}$. However, the overwhelming majority of MSCs were found in the lung after systemic administration in normal recipients, and these MSCs disap- 
peared gradually over time ${ }^{[54]}$. The mechanisms of these phenomena are still unclear.

The site of delivery most likely affects the trafficking of MSCs to target organs. Generally, two approaches of systemic administration have been used for MSC applications. One is intravenous injection, such as peripheral vein injection (tail vein in mice), utilizing the capabilities of MSCs to migrate to specific inflammatory tissues in vivo, including the cartilage, liver, and lung ${ }^{[5,56]}$. Engraftment was demonstrated in animal models and was capable of persisting for as long as 13 months after transplantation ${ }^{[53]}$. The other approach is local intraarterial injection, which can enhance the accumulation and increase the dose of MSCs in injured tissues. In a phase I study of MSCs as a treatment for liver cirrhosis in 2007, patients were injected with human MSCs through liver arteries $^{[57]}$. Moreover, to increase the number of MSCs and the efficiency of differentiation at the damaged sites, studies on liver cirrhosis, osteonecrosis, skin defects, and spinal cord injury employed local injections instead of the systemic administration of MSCs ${ }^{[31]}$. However, which route of administration is best for a particular disease and the possible contraindication of such clinical usage are still unknown.

\section{Time of MSC administration}

In addition to the different methods of administration, the timing of delivery and number of cells delivered are also very important. Sudres et al found in their study that MSCs failed to prevent GvHD in mice, and the failure was not due to MSC rejection $^{[58]}$. Meanwhile, our finding showed that MSCs could prolong survival in a GvHD mouse model ${ }^{[59]}$. One difference between these two studies was the infusion time of MSCs ${ }^{[60]}$. Sudres et al injected MSCs 10-15 min before GvHD induction, whereas we injected MSCs $3 \mathrm{~d}$ and $7 \mathrm{~d}$ after bone marrow transplantation. It is possible that the time of MSC administration is important for the therapeutic effect. Based on the above discussion that the immunosuppressive ability of MSCs must be induced by inflammatory cytokines, it is conceivable that MSC administration at the peak of inflammation may improve the treatment effect. However, this hypothesis needs to be further tested.

\section{Cell sources of MSCs}

MSCs exist in almost all tissues. They can be easily isolated from the bone marrow, adipose tissue, umbilical cord, fetal liver, muscle, and lung and can be successfully expanded in vitro ${ }^{[6-10]}$. Although the major source of MSCs in clinic trials is umbilical cord, recent studies have suggested that the allogenicity of MSCs have no significant adverse impact on the engraftment of MSCs in wound healing ${ }^{[61]}$. It is better to use freshly isolated MSCs because it has been shown that 5 major histocompatibility complex (MHC II) molecules could be increased during in vitro expansion ${ }^{[62,63]}$.

\section{Therapeutic mechanisms of MSCs}

As mentioned above, MSCs have displayed great potential in treating a large number of immune and non-immune diseases.
However, there are still major questions concerning the optimal dosage of MSCs, routes of administration, best engraftment time and the fate of the cells after infusion ${ }^{[64]}$. Thus, it is critical to explore the mechanisms governing MSC-based therapies. Although a uniform mechanism has not yet been discovered, the available data have revealed several working models for the beneficial effects of MSCs. Based on the current understanding, we summarize some key mechanisms that are significant in MSC-mediated therapies. It is noteworthy that for a given disease, multiple mechanisms are likely to contribute coordinately to the therapeutic effect of MSCs.

\section{Homing efficiency}

MSCs have a tendency to home to damaged tissue sites. When MSCs are delivered exogenously and systemically administered to humans and animals, they are always found to migrate specifically to damaged tissue sites with inflammation ${ }^{[65,66]}$, although many of the intravenously administered MSCs are trapped in the lung ${ }^{[67,68]}$. The inflammationdirected MSC homing has been demonstrated to involve several important cell trafficking-related molecules: chemokines, adhesion molecules, and matrix metalloproteinases (MMPs). Among these chemokines, the chemokine (C-X-C motif) ligand 12- chemokine (C-X-C motif) receptor 4 and chemokine (C-C motif) ligand 2- chemokine ( $C-C$ motif) receptor 2 axes are most studied ${ }^{[69,70]}$. Accordingly, CXCR4 was transduced into MSCs to improve their in vivo engraftment and therapeutic efficacy in a rat myocardial infarction model ${ }^{[71]}$. The adhesion molecule P-selectin and the VCAM-1 (vascular cell adhesion protein 1)-VLA-4 (very late antigen-4) interaction has been shown to be key mediators in MSC rolling and firm adherence to endothelial cells in vitro and in vivo ${ }^{[72]}$. Interestingly, in a recent report, VCAM-1 antibody-coated MSCs exhibited a higher efficiency of engraftment into inflamed mesenteric lymph nodes and the colon than uncoated MSCs in a mouse inflammatory bowel disease (IBD) model $^{[73]}$, suggesting that modulations of the homing property of MSCs could be a viable approach in enhancing their therapeutic effectiveness. In addition to chemokines and adhesion molecules, several MMPs, such as MMP-2 and membrane type 1 MMP (MT1MMP), have been shown to be essential in the invasiveness of $\operatorname{MSCs}^{[74,75]}$. It is worth noting that all the homing-related molecules can be up-regulated by inflammatory cytokines, such as TNF and IL-1 ${ }^{[76,77]}$. Therefore, different inflammation statuses (ie, different levels of inflammatory cytokines) might lead to distinct MSC engraftment and therapeutic efficiencies.

Tumors can be regarded as wounds that never heal and continuously generate various inflammatory cytokines ${ }^{[78]}$. Indeed, MSCs that are either de novo mobilized or exogenously administered have been found to migrate to tumors and adjacent tissue sites ${ }^{[79]}$. In view of this property, approaches have been developed to engineer several tumor-killing agents, such as IFNa, IFN $\beta$, IL-12, and TNF-related apoptosis-inducing ligand (TRAIL), in MSCs for tumor-targeted therapy in animal models ${ }^{[80-84]}$. More recently, MSCs have also been undergoing development as vehicles for the delivery of nanoparticles to 
enhance their tumoricidal effects ${ }^{[85,86]}$. Further investigations in this direction may lead to novel therapeutic strategies for cancer.

\section{Differentiation potential and tissue engineering}

As typical multipotent stem cells, MSCs have been shown to possess the capability to differentiate into a variety of cell types, including adipocytes, osteoblasts, chondrocytes, myoblasts and neuron-like cells. Although it is currently believed that the therapeutic benefits of MSCs are due to more complicated mechanisms, they have been indicated to be able to differentiate into osteoblasts, cardiomyocytes and other tissuespecific cells after their in vivo systemic infusion in the treatment of osteogenesis imperfecta and myocardial infarction in both animals and humans ${ }^{[53,87,88]}$.

In addition to systemic delivery, MSCs can be delivered together with various natural and synthetic biomaterial scaffolds. Either undifferentiated or differentiated MSCs can be loaded onto scaffolds before their implantation into damaged tissue sites ${ }^{[89,90]}$. Such technologies have been successfully applied in cartilage repair and long bone repair, with the generation of well-integrated and functional hard tissues ${ }^{[1,92]}$. The advantage of a tissue-engineered MSC delivery system lies in the ease of controlling and manipulating the implanted cells and tissues, with reduced side effects impacting other organs and tissues. Current improvements in delivery vehicles and compatibility between the scaffolds and MSCs will help to develop a mature technology for clinical applications.

\section{Production of trophic factors}

Accumulating evidence has revealed that the therapeutic benefits of MSCs are largely dependent on their capacity to act as a trophic factor pool. After MSCs home to damaged tissue sites for repair, they interact closely with local stimuli, such as inflammatory cytokines, ligands of Toll-like receptors (TLRs) and hypoxia, which can stimulate MSCs to produce a large amount of growth factors that perform multiple functions for tissue regeneration ${ }^{[93-95]}$. Many of these factors are critical mediators in angiogenesis and the prevention of cell apoptosis, such as vascular endothelial growth factor (VEGF), insulin-like growth factor 1 (IGF-1), basic fibroblast growth factors (bFGF), hepatocyte growth factor (HGF), IL-6 and CCL-2 ${ }^{[94,96,97]}$. Interestingly, a recent study found that the therapeutic effect of neuronal progenitors on EAE was solely dependent on leukemia inhibitory factor (LIF), revealing a similar trophic function as other tissue progenitors/stem cells ${ }^{[98]}$. Moreover, many reports have demonstrated that pre-treatment with growth factors or gene modification of MSCs can enhance the therapeutic efficacy for myocardial infarction and other woundhealing processes ${ }^{[99,100]}$. A further understanding of the molecular pathways involved in growth factor production will be helpful to develop better strategies for MSC-based therapies.

\section{Immunomodulation}

In the last few years, MSCs have been shown to be effective in treating various immune disorders in human and animal models. In both in vitro and in vivo studies, MSCs have been shown to suppress the excessive immune responses of $\mathrm{T}$ cells, B cells, dendritic cells, macrophages, and natural killer cells ${ }^{[101,102]}$. The underlying mechanisms are believed to be a combined effect of many immunosuppressive mediators. A majority of the mediators are inducible by inflammatory stimuli, such as nitric oxide (NO), indoleamine 2,3, dioxygenase (IDO), prostaglandin E2 (PGE2), tumor necrosis factorinducible gene 6 protein (TSG6), CCL-2, and programmed death ligand 1 (PD-L1) ${ }^{[68,103-108]}$. These factors are minimally expressed in unactivated MSCs unless they are stimulated by several inflammatory cytokines, such as IFN $\gamma, \mathrm{TNFa}$, and IL- ${ }^{[78,103]}$. The neutralization of either immunosuppressive effectors or inflammatory cytokines could reverse MSC-mediated immunosuppression ${ }^{[79]}$. The concept of inflammationlicensed immunosuppression favors a more rational design for the clinical use of MSCs. First, an optimal administration time point should be carefully selected according to the levels and ratios of different cytokines in the body during disease progression. Previous reports have demonstrated that MSC administration after disease onset may be better than at the same time of disease induction in a mouse GvHD model ${ }^{[71,79]}$. Second, cytokine priming should be attempted to improve the therapeutic effect of MSCs. Cheng et al reported that IFNYpretreated MSCs protected 100\% of mice from GvHD-induced death $^{[71]}$. Third, the therapeutic efficacy of MSCs most likely depends on the nature of different diseases due to the distinct inflammatory environments. Even for a specific disease, the diversity of microenvironments in different tissues may also produce different curative effects of MSCs. Therefore, the precise in vivo mechanism of MSCs may be more complex than observed in vitro. Further defining such mechanisms will help to develop better strategies for the clinical use of MSCs.

\section{Unsolved problems and challenges}

Although significant progress has been made in stem cell research in recent years, cell therapy with stem cells is far from a mature clinical technology. Because they are free of ethical concerns and have numerous sources, low immunogenicity and no teratoma risk, MSCs are the most commonly used stem cells in current clinical applications. However, there are still several major hurdles to their widespread utility. Further research is needed on interactions between MSCs and the inflammatory milieu in which they reside and the therapeutic mechanisms of MSCs. Furthermore, it is still not known which source should be used for which disease, which route of administration is best suited for a particular disease, and possible contraindications to their clinical use. Once administered, the parameters for monitoring clinical effectiveness also need to be established and are likely to vary for different disorders. Most importantly, established standards for cell expansion protocols, product quality, and safety controls are not available in most countries. Government regulatory agencies are eagerly waiting for detailed answers to these questions to establish regulatory polices to meet the challenges of this newly emerging and rapidly advancing field and benefit 
patients suffering a wide array of diseases. We look forward to using soluble products of MSCs instead of MSCs themselves in the future, which may simplify the administration of cells and make it safer.

\section{Acknowledgements}

This project was supported by the Key Basic Research Project of China (Grant No 2011CB966200, 2010CB945600, and 2011CB965100); Key Project of the National Natural Science Foundation of China (Grant No 81030041); the National Natural Science Foundation of China (Grant No 31171321 and 81101622); Special Funds for the National Key Sci-Tech Special Project of China (Grant No 2012ZX10002-016 and 2012ZX10002011-011); the Shanghai Science and Technology Committee (Grant No 11ZR1449500 and 12ZR1439800); and the Science Fund for Creative Research Groups, NSFC, China (Grant № 81221061).

\section{References}

1 Bianchi G, Borgonovo G, Pistoia V, Raffaghello L. Immunosuppressive cells and tumour microenvironment: focus on mesenchymal stem cells and myeloid derived suppressor cells. Histol Histopathol 2011; 26: 941-51.

2 Prockop DJ. Marrow stromal cells as stem cells for nonhematopoietic tissues. Science 1997; 276: 71-4.

3 Granero-Molto F, Weis JA, Longobardi L, Spagnoli A. Role of mesenchymal stem cells in regenerative medicine: application to bone and cartilage repair. Expert Opin Biol Ther 2008; 8: 255-68.

4 Salem HK, Thiemermann C. Mesenchymal stromal cells: current understanding and clinical status. Stem Cells 2010; 28: 585-96.

5 Dezawa M, Ishikawa H, Itokazu Y, Yoshihara T, Hoshino M, Takeda S, et al. Bone marrow stromal cells generate muscle cells and repair muscle degeneration. Science 2005; 309: 314-7.

6 Bianco P, Robey PG, Simmons PJ. Mesenchymal stem cells: revisiting history, concepts, and assays. Cell Stem Cell 2008; 2: 313-9.

7 Pittenger MF, Mackay AM, Beck SC, Jaiswal RK, Douglas R, Mosca JD, et al. Multilineage potential of adult human mesenchymal stem cells. Science 1999; 284: 143-7.

8 Anjos-Afonso F, Bonnet D. Nonhematopoietic/endothelial SSEA-1 $1^{+}$ cells define the most primitive progenitors in the adult murine bone marrow mesenchymal compartment. Blood 2007; 109: 1298-306.

9 In't Anker PS, Scherjon SA, Kleijburg-van der Keur C, de Groot-Swings GM, Claas FH, Fibbe WE, et al. Isolation of mesenchymal stem cells of fetal or maternal origin from human placenta. Stem Cells 2004; 22: 1338-45.

10 Zuk PA, Zhu M, Mizuno H, Huang J, Futrell JW, Katz AJ, et al. Multilineage cells from human adipose tissue: implications for cell-based therapies. Tissue Eng 2001; 7: 211-28.

11 Tzaribachev N, Vaegler M, Schaefer J, Reize P, Rudert M, Handgretinger R, et al. Mesenchymal stromal cells: a novel treatment option for steroid-induced avascular osteonecrosis. Isr Med Assoc J 2008; 10: 232-4.

12 Richardson SM, Hoyland JA. Stem cell regeneration of degenerated intervertebral discs: current status. Curr Pain Headache Rep 2008; 12: 83-8.

13 Amado LC, Saliaris AP, Schuleri KH, St John M, Xie JS, Cattaneo S, et al. Cardiac repair with intramyocardial injection of allogeneic mesenchymal stem cells after myocardial infarction. Proc Natl Acad Sci U S A 2005; 102: 11474-9.
14 Lee JW, Fang X, Gupta N, Serikov V, Matthay MA. Allogeneic human mesenchymal stem cells for treatment of $E$. coli endotoxin-induced acute lung injury in the ex vivo perfused human lung. Proc Natl Acad Sci U S A 2009; 106: 16357-62.

15 Parekkadan B, van Poll D, Suganuma K, Carter EA, Berthiaume F, Tilles AW, et al. Mesenchymal stem cell-derived molecules reverse fulminant hepatic failure. PLoS One 2007; 2: e941.

16 Togel F, Hu Z, Weiss K, Isaac J, Lange C, Westenfelder C. Administered mesenchymal stem cells protect against ischemic acute renal failure through differentiation-independent mechanisms. Am J Physiol Renal Physiol 2005; 289: F31-42.

17 Kim JM, Lee ST, Chu K, Jung KH, Song EC, Kim SJ, et al. Systemic transplantation of human adipose stem cells attenuated cerebral inflammation and degeneration in a hemorrhagic stroke model. Brain Res 2007; 1183: 43-50.

18 Inoue $\mathrm{Y}$, Iriyama A, Ueno S, Takahashi H, Kondo M, Tamaki Y, et al. Subretinal transplantation of bone marrow mesenchymal stem cells delays retinal degeneration in the RCS rat model of retinal degeneration. Exp Eye Res 2007; 85: 234-41.

19 Chen L, Tredget EE, Wu PY, Wu Y. Paracrine factors of mesenchymal stem cells recruit macrophages and endothelial lineage cells and enhance wound healing. PLoS One 2008; 3: e1886.

20 Hayashi Y, Tsuji S, Tsujii M, Nishida T, Ishii S, lijima H, et al. Topical implantation of mesenchymal stem cells has beneficial effects on healing of experimental colitis in rats. J Pharmacol Exp Ther 2008; 326: 523-31.

21 Zappia E, Casazza S, Pedemonte E, Benvenuto F, Bonanni I, Gerdoni E, et al. Mesenchymal stem cells ameliorate experimental autoimmune encephalomyelitis inducing T-cell anergy. Blood 2005; 106: 175561.

22 Horwitz EM, Prockop DJ, Fitzpatrick LA, Koo WW, Gordon PL, Neel $\mathrm{M}$, et al. Transplantability and therapeutic effects of bone marrowderived mesenchymal cells in children with osteogenesis imperfecta. Nat Med 1999; 5: 309-13.

23 Garcia-OImo D, Garcia-Arranz M, Herreros D, Pascual I, Peiro C, Rodriguez-Montes JA. A phase I clinical trial of the treatment of Crohn's fistula by adipose mesenchymal stem cell transplantation. Dis Colon Rectum 2005; 48: 1416-23.

24 Le Blanc K, Rasmusson I, Sundberg B, Gotherstrom C, Hassan M, Uzunel M, et al. Treatment of severe acute graft-versus-host disease with third party haploidentical mesenchymal stem cells. Lancet 2004; 363: 1439-41.

25 Noth U, Steinert AF, Tuan RS. Technology insight: adult mesenchymal stem cells for osteoarthritis therapy. Nat Clin Pract Rheumatol 2008; 4: 371-80.

26 Erokhin VV, Vasil'eva IA, Konopliannikov AG, Chukanov VI, Tsyb AF, Bagdasarian TR, et al. Systemic transplantation of autologous mesenchymal stem cells of the bone marrow in the treatment of patients with multidrug-resistant pulmonary tuberculosis. Probl Tuberk Bolezn Legk 2008; (10): 3-6.

27 Peng L, Xie DY, Lin BL, Liu J, Zhu HP, Xie C, et al. Autologous bone marrow mesenchymal stem cell transplantation in liver failure patients caused by hepatitis B: short-term and long-term outcomes. Hepatology 2011; 54: 820-8.

28 Kharaziha P, Hellstrom PM, Noorinayer B, Farzaneh F, Aghajani K, Jafari $F$, et al. Improvement of liver function in liver cirrhosis patients after autologous mesenchymal stem cell injection: a phase I-II clinical trial. Eur J Gastroenterol Hepatol 2009; 21: 1199-205.

29 Lu D, Chen B, Liang Z, Deng W, Jiang Y, Li S, et al. Comparison of bone marrow mesenchymal stem cells with bone marrow-derived mononuclear cells for treatment of diabetic critical limb ischemia 
and foot ulcer: a double-blind, randomized, controlled trial. Diabetes Res Clin Pract 2011; 92: 26-36.

30 Yamada Y, Ueda M, Hibi H, Baba S. A novel approach to periodontal tissue regeneration with mesenchymal stem cells and platelet-rich plasma using tissue engineering technology: a clinical case report. Int J Periodontics Restorative Dent 2006; 26: 363-9.

31 Rasulov MF, Vasilchenkov AV, Onishchenko NA, Krasheninnikov ME, Kravchenko VI, Gorshenin TL, et al. First experience of the use bone marrow mesenchymal stem cells for the treatment of a patient with deep skin burns. Bull Exp Biol Med 2005; 139: 141-4.

32 Lee RH, Pulin AA, Seo MJ, Kota DJ, Ylostalo J, Larson BL, et al. Intravenous hMSCs improve myocardial infarction in mice because cells embolized in lung are activated to secrete the anti-inflammatory protein TSG-6. Cell Stem Cell 2009; 5: 54-63.

33 Roddy GW, Oh JY, Lee RH, Bartosh TJ, Ylostalo J, Coble K, et al. Action at a distance: systemically administered adult stem/progenitor cells (MSCs) reduce inflammatory damage to the cornea without engraftment and primarily by secretion of TSG-6. Stem Cells 2011; 29: 1572-9.

34 Zeng $X$, Zeng YS, Ma YH, Lu LY, Du BL, Zhang W, et al. Bone marrow mesenchymal stem cells in a three dimensional gelatin sponge scaffold attenuate inflammation, promote angiogenesis and reduce cavity formation in experimental spinal cord injury. Cell Transplant 2011; 20: 1881-99.

35 Ortiz LA, Dutreil M, Fattman C, Pandey AC, Torres G, Go K, et al. Interleukin 1 receptor antagonist mediates the antiinflammatory and antifibrotic effect of mesenchymal stem cells during lung injury. Proc Natl Acad Sci U S A 2007; 104: 11002-7.

36 Goodwin M, Sueblinvong V, Eisenhauer P, Ziats NP, LeClair L, Poynter $\mathrm{ME}$, et al. Bone marrow-derived mesenchymal stromal cells inhibit Th2-mediated allergic airways inflammation in mice. Stem Cells 2011; 29: 1137-48.

37 Chapel A, Bertho JM, Bensidhoum M, Fouillard L, Young RG, Frick $J$, et al. Mesenchymal stem cells home to injured tissues when coinfused with hematopoietic cells to treat a radiation-induced multiorgan failure syndrome. J Gene Med 2003; 5: 1028-38.

38 Muller I, Kordowich S, Holzwarth C, Isensee G, Lang P, Neunhoeffer $\mathrm{F}$, et al. Application of multipotent mesenchymal stromal cells in pediatric patients following allogeneic stem cell transplantation. Blood Cells Mol Dis 2008; 40: 25-32.

39 Prasad VK, Lucas KG, Kleiner GI, Talano JA, Jacobsohn D, Broadwater $G$, et al. Efficacy and safety of ex vivo cultured adult human mesenchymal stem cells (Prochymal) in pediatric patients with severe refractory acute graft-versus-host disease in a compassionate use study. Biol Blood Marrow Transplant 2011; 17: 534-41.

40 Kebriaei P, Isola L, Bahceci E, Holland K, Rowley S, McGuirk J, et al. Adult human mesenchymal stem cells added to corticosteroid therapy for the treatment of acute graft-versus-host disease. Biol Blood Marrow Transplant 2009; 15: 804-11.

41 Wu KH, Chan CK, Tsai C, Chang YH, Sieber M, Chiu TH, et al. Effective treatment of severe steroid-resistant acute graft-versushost disease with umbilical cord-derived mesenchymal stem cells. Transplantation 2011; 91: 1412-6.

42 Le Blanc K, Frassoni F, Ball L, Locatelli F, Roelofs H, Lewis I, et al. Mesenchymal stem cells for treatment of steroid-resistant, severe, acute graft-versus-host disease: a phase II study. Lancet 2008; 371 : 1579-86.

43 Sun L, Wang D, Liang J, Zhang $\mathrm{H}$, Feng $\mathrm{X}$, Wang $\mathrm{H}$, et al. Umbilical cord mesenchymal stem cell transplantation in severe and refractory systemic lupus erythematosus. Arthritis Rheum 2010; 62: 2467-75.

44 Carrion F, Nova E, Ruiz C, Diaz F, Inostroza C, Rojo D, et al. Auto- logous mesenchymal stem cell treatment increased T regulatory cells with no effect on disease activity in two systemic lupus erythematosus patients. Lupus 2010; 19: 317-22.

45 Ciccocioppo R, Bernardo ME, Sgarella A, Maccario R, Avanzini MA, Ubezio $\mathrm{C}$, et al. Autologous bone marrow-derived mesenchymal stromal cells in the treatment of fistulising Crohn's disease. Gut 2011; 60: 788-98.

46 Duijvestein M, Vos AC, Roelofs H, Wildenberg ME, Wendrich BB, Verspaget HW, et al. Autologous bone marrow-derived mesenchymal stromal cell treatment for refractory luminal Crohn's disease: results of a phase I study. Gut 2010; 59: 1662-9.

47 Lee PH, Kim JW, Bang OY, Ahn YH, Joo IS, Huh K. Autologous mesenchymal stem cell therapy delays the progression of neurological deficits in patients with multiple system atrophy. Clin Pharmacol Ther 2008; 83: 723-30.

48 Karussis D, Karageorgiou C, Vaknin-Dembinsky A, Gowda-Kurkalli B, Gomori JM, Kassis I, et al. Safety and immunological effects of mesenchymal stem cell transplantation in patients with multiple sclerosis and amyotrophic lateral sclerosis. Arch Neurol 2010; 67: 1187-94.

49 Connick P, Kolappan M, Patani R, Scott MA, Crawley C, He XL, et al. The mesenchymal stem cells in multiple sclerosis (MSCIMS) trial protocol and baseline cohort characteristics: an open-label pre-test: post-test study with blinded outcome assessments. Trials 2011; 12 : 62.

50 Choi MR, Kim HY, Park JY, Lee TY, Baik CS, Chai YG, et al. Selection of optimal passage of bone marrow-derived mesenchymal stem cells for stem cell therapy in patients with amyotrophic lateral sclerosis. Neurosci Lett 2010; 472: 94-8.

51 Honmou O, Houkin K, Matsunaga T, Niitsu Y, Ishiai S, Onodera R, et al. Intravenous administration of auto serum-expanded autologous mesenchymal stem cells in stroke. Brain 2011; 134: 1790-807.

52 Mannon PJ. Remestemcel-L: human mesenchymal stem cells as an emerging therapy for Crohn's disease. Expert Opin Biol Ther 2011; 11: 1249-56.

53 Liechty KW, MacKenzie TC, Shaaban AF, Radu A, Moseley AM, Deans $\mathrm{R}$, et al. Human mesenchymal stem cells engraft and demonstrate site-specific differentiation after in utero transplantation in sheep. Nat Med 2000; 6: 1282-6.

54 Lama VN, Smith L, Badri L, Flint A, Andrei AC, Murray S, et al. Evidence for tissue-resident mesenchymal stem cells in human adult lung from studies of transplanted allografts. J Clin Invest 2007; 117: 989-96.

55 Sakaida I, Terai S, Yamamoto N, Aoyama K, Ishikawa T, Nishina H, et al. Transplantation of bone marrow cells reduces $\mathrm{CCl}_{4}$-induced liver fibrosis in mice. Hepatology 2004; 40: 1304-11.

56 Chen J, Li Y, Wang L, Zhang Z, Lu D, Lu M, et al. Therapeutic benefit of intravenous administration of bone marrow stromal cells after cerebral ischemia in rats. Stroke 2001; 32: 1005-11.

57 Mohamadnejad M, Namiri M, Bagheri M, Hashemi SM, Ghanaati $\mathrm{H}$, Zare Mehrjardi N, et al. Phase 1 human trial of autologous bone marrow-hematopoietic stem cell transplantation in patients with decompensated cirrhosis. World J Gastroenterol 2007; 13: 335963.

58 Sudres M, Norol F, Trenado A, Gregoire S, Charlotte F, Levacher B, et al. Bone marrow mesenchymal stem cells suppress lymphocyte proliferation in vitro but fail to prevent graft-versus-host disease in mice. J Immunol 2006; 176: 7761-7.

59 Ren G, Zhang L, Zhao X, Xu G, Zhang Y, Roberts Al, et al. Mesenchymal stem cell-mediated immunosuppression occurs via concerted action of chemokines and nitric oxide. Cell Stem Cell 2008; 2: 141- 
50.

60 Shi Y, Hu G, Su J, Li W, Chen Q, Shou P, et al. Mesenchymal stem cells: a new strategy for immunosuppression and tissue repair. Cell Res 2010; 20: 510-8.

61 Chen L, Tredget EE, Liu C, Wu Y. Analysis of allogenicity of mesenchymal stem cells in engraftment and wound healing in mice. PLoS One 2009; 4: e7119.

62 Tarte K, Gaillard J, Lataillade JJ, Fouillard L, Becker M, Mossafa H, et al. Clinical-grade production of human mesenchymal stromal cells: occurrence of aneuploidy without transformation. Blood 2010; 115: 1549-53.

63 Bocelli-Tyndall C, Zajac P, Di Maggio N, Trella E, Benvenuto F, lezzi $\mathrm{G}$, et al. Fibroblast growth factor 2 and platelet-derived growth factor, but not platelet lysate, induce proliferation-dependent, functional class II major histocompatibility complex antigen in human mesenchymal stem cells. Arthritis Rheum 2010; 62: 3815-25.

64 Karp JM, Leng Teo GS. Mesenchymal stem cell homing: the devil is in the details. Cell Stem Cell 2009; 4: 206-16.

65 Horwitz EM, Gordon PL, Koo WK, Marx JC, Neel MD, McNall RY, et al. Isolated allogeneic bone marrow-derived mesenchymal cells engraft and stimulate growth in children with osteogenesis imperfecta: Implications for cell therapy of bone. Proc Natl Acad Sci U S A 2002; 99: 8932-7.

66 Mahmood A, Lu D, Lu M, Chopp M. Treatment of traumatic brain injury in adult rats with intravenous administration of human bone marrow stromal cells. Neurosurgery 2003; 53: 697-702.

67 Barbash IM, Chouraqui P, Baron J, Feinberg MS, Etzion S, Tessone A, et al. Systemic delivery of bone marrow-derived mesenchymal stem cells to the infarcted myocardium: feasibility, cell migration, and body distribution. Circulation 2003; 108: 863-8.

68 Lee RH, Pulin AA, Seo MJ, Kota DJ, Ylostalo J, Larson BL, et al. Intravenous hMSCs improve myocardial infarction in mice because cells embolized in lung are activated to secrete the anti-inflammatory protein TSG-6. Cell Stem Cell 2009; 5: 54-63.

69 Wynn RF, Hart CA, Corradi-Perini C, O'Neill L, Evans CA, Wraith JE, et al. A small proportion of mesenchymal stem cells strongly expresses functionally active CXCR4 receptor capable of promoting migration to bone marrow. Blood 2004; 104: 2643-5.

70 Belema-Bedada F, Uchida S, Martire A, Kostin S, Braun T. Efficient homing of multipotent adult mesenchymal stem cells depends on FROUNT-mediated clustering of CCR2. Cell Stem Cell 2008; 2: 56675.

71 Cheng Z, Ou L, Zhou X, Li F, Jia X, Zhang Y, et al. Targeted migration of mesenchymal stem cells modified with CXCR4 gene to infarcted myocardium improves cardiac performance. Mol Ther 2008; 16 : 571-9.

72 Ruster B, Gottig S, Ludwig RJ, Bistrian R, Muller S, Seifried E, et al. Mesenchymal stem cells display coordinated rolling and adhesion behavior on endothelial cells. Blood 2006; 108: 3938-44.

73 Ko IK, Kim BG, Awadallah A, Mikulan J, Lin P, Letterio JJ, et al. Targeting improves MSC treatment of inflammatory bowel disease. Mol Ther 2010; 18: 1365-72.

74 Ries C, Egea V, Karow M, Kolb H, Jochum M, Neth P. MMP-2, MT1MMP, and TIMP-2 are essential for the invasive capacity of human mesenchymal stem cells: differential regulation by inflammatory cytokines. Blood 2007; 109: 4055-63.

75 Ding Y, Xu D, Feng G, Bushell A, Muschel RJ, Wood KJ. Mesenchymal stem cells prevent the rejection of fully allogenic islet grafts by the immunosuppressive activity of matrix metalloproteinase-2 and -9 . Diabetes 2009; 58: 1797-806.

76 Shi M, Li J, Liao L, Chen B, Li B, Chen L, et al. Regulation of CXCR4 expression in human mesenchymal stem cells by cytokine treatment: role in homing efficiency in NOD/SCID mice. Haematologica 2007; 92: 897-904.

77 Ren G, Zhao X, Zhang L, Zhang J, L'Huillier A, Ling W, et al. Inflammatory cytokine-induced intercellular adhesion molecule-1 and vascular cell adhesion molecule-1 in mesenchymal stem cells are critical for immunosuppression. J Immunol 2010; 184: 2321-8.

78 Dvorak HF. Tumors: wounds that do not heal. Similarities between tumor stroma generation and wound healing. N Engl J Med 1986; 315: 1650-9.

79 Spaeth E, Klopp A, Dembinski J, Andreeff M, Marini F. Inflammation and tumor microenvironments: defining the migratory itinerary of mesenchymal stem cells. Gene Ther 2008; 15: 730-8.

80 Studeny M, Marini FC, Champlin RE, Zompetta C, Fidler IJ, Andreeff M. Bone marrow-derived mesenchymal stem cells as vehicles for interferon-beta delivery into tumors. Cancer Res 2002; 62: 3603-8.

81 Ren C, Kumar S, Chanda D, Kallman L, Chen J, Mountz JD, et al. Cancer gene therapy using mesenchymal stem cells expressing interferon-beta in a mouse prostate cancer lung metastasis model. Gene Ther 2008; 15: 1446-53.

82 Seo SH, Kim KS, Park SH, Suh YS, Kim SJ, Jeun SS, et al. The effects of mesenchymal stem cells injected via different routes on modified IL-12-mediated antitumor activity. Gene Ther 2011; 18: 488-95.

83 Loebinger MR, Eddaoudi A, Davies D, Janes SM. Mesenchymal stem cell delivery of TRAIL can eliminate metastatic cancer. Cancer Res 2009; 69: 4134-42.

84 Ren C, Kumar S, Chanda D, Chen J, Mountz JD, Ponnazhagan S. Therapeutic potential of mesenchymal stem cells producing interferon-alpha in a mouse melanoma lung metastasis model. Stem Cells 2008; 26: 2332-8.

85 Roger M, Clavreul A, Venier-Julienne MC, Passirani C, Sindji L, Schiller $P$, et al. Mesenchymal stem cells as cellular vehicles for delivery of nanoparticles to brain tumors. Biomaterials 2010; 31: 8393-401.

86 Cheng H, Kastrup CJ, Ramanathan R, Siegwart DJ, Ma M, Bogatyrev $\mathrm{SR}$, et al. Nanoparticulate cellular patches for cell-mediated tumoritropic delivery. ACS Nano 2010; 4: 625-31.

87 Horwitz EM, Gordon PL, Koo WK, Marx JC, Neel MD, McNall RY, et al. Isolated allogeneic bone marrow-derived mesenchymal cells engraft and stimulate growth in children with osteogenesis imperfecta: Implications for cell therapy of bone. Proc Natl Acad Sci U S A 2002; 99: 8932-7.

88 Kawada H, Fujita J, Kinjo K, Matsuzaki Y, Tsuma M, Miyatake H, et al. Nonhematopoietic mesenchymal stem cells can be mobilized and differentiate into cardiomyocytes after myocardial infarction. Blood 2004; 104: 3581-7.

89 Dennis JE, Konstantakos EK, Arm D, Caplan Al. In vivo osteogenesis assay: a rapid method for quantitative analysis. Biomaterials 1998; 19: 1323-8.

90 Ohgushi H, Kotobuki N, Funaoka H, Machida H, Hirose M, Tanaka Y, et al. Tissue engineered ceramic artificial joint - ex vivo osteogenic differentiation of patient mesenchymal cells on total ankle joints for treatment of osteoarthritis. Biomaterials 2005; 26: 4654-61.

91 Kon E, Muraglia A, Corsi A, Bianco P, Marcacci M, Martin I, et al. Autologous bone marrow stromal cells loaded onto porous hydroxyapatite ceramic accelerate bone repair in critical-size defects of sheep long bones. J Biomed Mater Res 2000; 49: 328-37.

92 Solchaga LA, Temenoff JS, Gao J, Mikos AG, Caplan AI, Goldberg VM. Repair of osteochondral defects with hyaluronan- and polyesterbased scaffolds. Osteoarthritis Cartilage 2005; 13: 297-309.

93 Crisostomo PR, Wang Y, Markel TA, Wang M, Lahm T, Meldrum DR. Human mesenchymal stem cells stimulated by TNF-alpha, LPS, 
or hypoxia produce growth factors by an NF kappa B- but not JNKdependent mechanism. Am J Physiol Cell Physiol 2008; 294: C67582.

94 Caplan Al, Dennis JE. Mesenchymal stem cells as trophic mediators. J Cell Biochem 2006; 98: 1076-84.

95 Jing Y, Han Z, Zhang S, Liu Y, Wei L. Epithelial-mesenchymal transition in tumor microenvironment. Cell Biosci 2011; 1: 29.

96 Xu G, Zhang Y, Zhang L, Ren G, Shi Y. The role of IL-6 in inhibition of lymphocyte apoptosis by mesenchymal stem cells. Biochem Biophys Res Commun 2007; 361: 745-50.

97 Liu Y, Han ZP, Zhang SS, Jing YY, Bu XX, Wang CY, et al. Effects of inflammatory factors on mesenchymal stem cells and their role in the promotion of tumor angiogenesis in colon cancer. J Biol Chem 2011; 286: 25007-15.

98 Cao W, Yang Y, Wang Z, Liu A, Fang L, Wu F, et al. Leukemia inhibitory factor inhibits $\mathrm{T}$ helper 17 cell differentiation and confers treatment effects of neural progenitor cell therapy in autoimmune disease. Immunity 2011; 35: 273-84.

99 Hahn JY, Cho HJ, Kang HJ, Kim TS, Kim MH, Chung JH, et al. Pretreatment of mesenchymal stem cells with a combination of growth factors enhances gap junction formation, cytoprotective effect on cardiomyocytes, and therapeutic efficacy for myocardial infarction. J Am Coll Cardiol 2008; 51: 933-43.

100 Schnabel LV, Lynch ME, van der Meulen MC, Yeager AE, Kornatowski MA, Nixon AJ. Mesenchymal stem cells and insulin-like growth factor-I gene-enhanced mesenchymal stem cells improve structural aspects of healing in equine flexor digitorum superficialis tendons. $J$ Orthop Res 2009; 27: 1392-8.
101 Uccelli A, Moretta L, Pistoia V. Mesenchymal stem cells in health and disease. Nat Rev Immunol 2008; 8: 726-36.

102 Han Z, Jing Y, Zhang S, Liu Y, Shi Y, Wei L. The role of immunosuppression of mesenchymal stem cells in tissue repair and tumor growth. Cell Biosci 2012; 2: 8.

103 Kanichai M, Ferguson D, Prendergast PJ, Campbell VA. Hypoxia promotes chondrogenesis in rat mesenchymal stem cells: a role for AKT and hypoxia-inducible factor (HIF)-1alpha. J Cell Physiol 2008; 216: 708-15.

104 Krampera M, Cosmi L, Angeli R, Pasini A, Liotta F, Andreini A, et al. Role for interferon-gamma in the immunomodulatory activity of human bone marrow mesenchymal stem cells. Stem Cells 2006; 24 : 386-98.

105 Aggarwal S, Pittenger MF. Human mesenchymal stem cells modulate allogeneic immune cell responses. Blood 2005; 105: 1815-22.

106 Rafei M, Campeau PM, Aguilar-Mahecha A, Buchanan M, Williams P, Birman E, et al. Mesenchymal stromal cells ameliorate experimental autoimmune encephalomyelitis by inhibiting CD4 Th17 T cells in a CC chemokine ligand 2-dependent manner. J Immunol 2009; 182: 5994-6002.

107 Augello A, Tasso R, Negrini SM, Amateis A, Indiveri F, Cancedda R, et al. Bone marrow mesenchymal progenitor cells inhibit lymphocyte proliferation by activation of the programmed death 1 pathway. Eur J Immunol 2005; 35: 1482-90.

108 Nemeth K, Leelahavanichkul A, Yuen PS, Mayer B, Parmelee A, Doi K, et al. Bone marrow stromal cells attenuate sepsis via prostaglandin $\mathrm{E}_{2}$-dependent reprogramming of host macrophages to increase their interleukin-10 production. Nat Med 2009; 15: 42-9. 